DOI 10.14409/fa.v21i1.11112

\title{
Influencia de un complejo viral en rendimiento y contenido de clorofila de dos variedades de batata
}

\author{
Buxmann, E. ${ }^{1 ;}$ Vilanova Perez, A. ${ }^{1 ;}$ López Colomba, E. ${ }^{1 ;}$ \\ Suasnabar, R. ${ }^{1}$; Luque, A. ${ }^{1}$; Araujo Vieira de Souza, J.C. ${ }^{2} \&$ Di Feo, L. ${ }^{1}$
}

\section{RESUMEN}

Las virosis son la principal limitante del rendimiento de batata, quinto cultivo alimenticio del mundo. En Argentina, el "encrespamiento amarillo" (EA), complejo viral con siete agentes involucrados, causa notables pérdidas en los genotipos de toda región productiva. Se analizó la influencia del EA en componentes de rendimiento de los cvs Arapey INIA y Beauregard. mediante ensayos comparativos que combinaron dos condiciones sanitarias (sana vs enferma) y dos genotipos. Las plantas sanas se obtuvieron por termoterapia y cultivo in vitro de meristemas, y las enfermas, injertando púas con EA. Hubo diferencias significativas entre condiciones sanitarias, para contenido de clorofilas y mermas de caracteres de rendimiento cercanas al $90 \%$, donde peso y número de raíces comerciales fueron los más afectados por EA en ambas variedades. Se corrobora la relevancia del EA como limitante del cultivo y del empleo de materiales saneados junto a buenas prácticas de manejo para alcanzar rendimientos potenciales.

Palabras clave: Ipomoea batatas, encrespamiento amarillo, complejo viral, producción de raíces, fotosintesis.

1.- Instituto de Patología Vegetal, Centro de Investigaciones Agropecuarias, IPAVE - CIAP - INTA (ex-IFFIVE), Camino 60 Cuadras Km 5 1/2, X5014MGO, Córdoba, Argentina. E-mail: aberdeenerik@gmail.com*, ldifeoar@yahoo.com.ar

2.- Facultad de Ciencias Agrarias, Universidad Nacional del Litoral. Kreder 2805. (3080HOF) Esperanza, provincia de Santa Fe, Argentina. E-mail: jaraujo@fca.unl.edu.ar

*Email de autor para correspondencia: aberdeenerik@gmail.com Manuscrito recibido el 2 de marzo de 2021 y aceptado para su publicación el $1^{\circ}$ de septiembre de 2021.

Buxmann, E.; Vilanova Perez, A.; López Colomba, E.; Suasnabar, R.; Luque, A.; Araujo Vieira de Souza, J.C.; Di Feo, L. Influencia de un complejo viral en rendimiento y contenido de clorofila de dos variedades de batata. FAVE - Ciencias Agrarias 21 (1): 31-47 - CC BY-NC-SA 4.0 


\begin{abstract}
Influence of a viral complex on yield and chlorophyl content of two varieties of sweet potato.

Virus diseases are the main constraint of sweet potato yield, the fifth largest food crop. In Argentina, "yellow curling" (EA), a viral complex with seven agents involved, causes notable losses in all the growing regions. The influence of EA on yield components of Arapey INIA and Beauregard cultivars was analyzed by comparative trials that combined two health conditions and two genotypes. Healthy plants were obtained by thermotherapy and in vitro culture of meristems and the diseased ones, by grafting with EA. There were significant differences between health conditions, in chlorophyll content and losses in yield characters near to $90 \%$. Weight and number of commercial roots were the most affected by EA in both cultivars. This work corroborates the relevance of EA on sweet potato production. Virus free plants and good management practices increase greatly the yields.
\end{abstract}

Key words: Ipomoea batatas, yellow curling, virus complex, root production, photosynthesis.

\section{INTRODUCCIÓN}

A nivel global, las virosis de batata constituyen potencialmente la limitante de su producción de mayor relevancia, ocasionando consecuentemente, la disminución de su superficie cultivada (Loebenstein, 2015). En el mundo, se citan cerca de 30 virus de batata (Clark et al., 2012) y en nuestro país hasta el presente, han sido detectados nueve (Di Feo et al., 2000; Nome et al. 2005; Rodríguez Pardina et al., 2012a; Rodríguez Pardina et al., 2012b; Bejerman et al., 2016; Martino et al., 2017a; Martino et al., 2017b).

La propagación comercial vegetativa de la especie conduce a un incremento en la concentración de partículas virales y a su perpetuación en los tejidos vegetales, en perjuicio de los rendimientos (Loebenstein et al., 2009). Argentina no escapa a este fenómeno global, del cual las virosis son una de las principales causas. Estas patologías tuvieron aparición cíclica en nuestro país desde los '70, en que Sweet potato vein mosaic virus (SPVMV), causal de "batata crespa", generó severos daños en los rendimientos del cultivar cv Criolla Amarilla (Nome, 1973; Nome y Docampo, 1974). Un programa de producción y distribución de plantines libres de virus permitió la recuperación de los cultivos. Sin embargo, en la década del 80, el "enanismo clorótico" (Di Feo et al., 2000), provocado por un complejo de tres virus: Sweet potato chlorotic stunt virus (SPCSV), sinérgico con Sweet potato feathery mottle virus (SPFMV) y con otro potyvirus. Sweet potato mild speckling virus (SPMSV), afectó gravemente al cv Morada INTA (Biderbost et al., 1990). Esto se debió a la discontinuidad en el empleo de plantines de sanidad controlada, única medida eficiente de control disponible hasta la fecha (Loebenstein, 2015). 
Desde 2009, las virosis son responsables de severos daños en la producción, causando mermas superiores al $90 \%$, lo que implica un grave problema social (Tolocka et al., 2012a), pues productores tradicionales abandonan el cultivo con consecuencias perjudiciales para las diferentes regiones.

La plantación de estacas de tallo (guías) o de plantines infectados es la vía más importante de diseminación de los patógenos virales de un ciclo de cultivo a otro (infección secundaria), que conlleva un incremento de la concentración de viriones en los tejidos. Las infecciones primarias ocurren por contagio entre plantas mediante vectores, en su mayoría insectos hemípteros, con aparato bucal picador-suctor, como áfidos o pulgones y aleuródidos o moscas blancas (infecciones primarias). Los virus son transmitidos de manera "no persistente" por pulgones y semipersistente o persistente por moscas blancas (Salazar, 1996; Di Feo, 2015).

El calentamiento global ha desencadenado cambios en los patosistemas y el consiguiente desplazamiento de insectos como B. tabaci, vector de geminivirus y de SPCSV, desde regiones tropicales y subtropicales hacia otras, antes consideradas templadas (Galvez et al., 2013). Observaciones efectuadas en diferentes lotes de regiones productoras de Argentina, como NEA, NOA, Región Pampeana, y Cuyo, permitieron establecer la presencia de una patología viral denominada "encrespamiento amarillo" (EA), con elevada incidencia en diversas variedades en las que ocasiona síntomas severos que podemos resumir en notable disminución del crecimiento vegetativo de la planta, distorsión de láminas foliares y marcada manifestación de clorosis. Esto conlleva mermas potenciales y significativas en los componentes de ren- dimiento, en lotes de producción y en ensayos experimentales y, además, afecta la calidad comercial de las batatas. El contenido de carotenos, precursores de vitamina A, se ve reducido notablemente en las raíces reservantes procedentes de plantas infectadas (López Colomba et al., 2011; Tolocka et al., 2012b), lo cual constituye un grave problema ya que, en la actualidad, se mejora el cultivo para lograr niveles mayores de dicha vitamina y se emplean, de manera creciente, variedades cuya pulpa de raíz es amarilla o anaranjada.

Los agentes causales del EA forman parte de un complejo viral de siete patógenos, seis de ellos no citados anteriormente en Argentina y que se resaltan en negrita: tres potyvirus transmitidos de manera no persistente por Myzus persicae: SPFMV (razas russet crack: RC y ordinary: O), Sweet potato virus G (SPVG), Sweet potato virus C (SPVC); el crinivirus SPCSV-WA (raza Western África) y los geminivirus Sweet potato leaf curl virus (SPLCV), Sweet potato leaf curl Georgia virus (SPLCGV-Ar) transmitidos por B. tabaci (transmisión semi-persistente en el caso del crinivirus y persistente en el de los geminivirus). Recientemente fue identificado Sweet potato symptomless virus 1 (SPSMV-1), geminivirus del género Mastrevirus. SPCSV se destaca por su efecto sinérgico en infecciones mixtas principalmente con los potyvirus. El complejo EA genera una variada y severa sintomatología (clorosis, achaparramiento, mosaico, diseños cloróticos, reducción y ampollado de la hoja, entre otros) e importantes daños en la producción y calidad comercial (López Colomba et at., 2011; Tolocka et al., 2012a; Tolocka et al., 2012b). Además de los síntomas severos, las co-infecciones entre virus causan reducción en el contenido de clorofila y, consecuentemente, 
en la radiación fotosintéticamente activa y el rendimiento (Wang et al., 2019).

A causa de su gran diversidad genética y la consiguiente variabilidad en sus características fenotípicas y morfológicas, la batata presenta amplia adaptabilidad y versatilidad de usos y demanda creciente, por lo que las infecciones virales adquieren relevancia como principal limitante de su producción. En los últimos años, viene adquiriendo progresiva importancia como alimento saludable y por sus potenciales usos industriales.

El objetivo de este trabajo fue determinar, experimentalmente, la influencia de la virosis actual (EA) en el rendimiento y en el contenido de clorofila de dos cultivares de batata de gran relevancia en Argentina: Arapey INIA, el de mayor distribución en todas las regiones cultivadas y Beauregard, promisorio por su alto contenido de carotenos, sus posibles aplicaciones en la industria alimenticia y su demanda en el mercado externo.

\section{MATERIALES Y MÉTODOS}

\section{Regeneración y saneamiento de dos cultivares de batata}

La regeneración y saneamiento de plantas de los cultivares de batata incluidos en este estudio (Arapey INIA y Beauregard) se llevó a cabo en cuatro pasos (CIAT, 1982; Love et al., 1987). En primer lugar, se eligieron las plantas dadoras de meristemas que respondían al tipo varietal de los dos cultivares a las que, previo a la extracción de meristemas, se le efectuó control sanitario a través de las pruebas que se indican más abajo. Dichas plantas madre, fueron llevadas a termoterapia $\left(37-38^{\circ} \mathrm{C}, 16 \mathrm{~h}\right.$ de luz y 3000 lux de intensidad lumínica por tres semanas), a la que siguió el cultivo in vitro de meristemas, de yemas apicales por su mayor crecimiento potencial, bajo condiciones de asepsia adecuadas. El medio agarizado contenía sales minerales (Murashige y Skoog, 1962), vitaminas, sacarosa y auxinas. La incubación fue a $25^{\circ} \mathrm{C}, 18 \mathrm{~h}$ de luz y 5000 lux de intensidad lumínica y a los 45 días se regeneró una planta completa (Nome y Salvadores, 1980). Antes de su micropropagación, las plantas regeneradas se sometieron a control sanitario. Para ello, se escindieron en 8-10 microestacas, y se colocaron en medio de cultivo sin hormonas, en cámara de flujo laminar. La mitad de las plantas hermanas regeneradas se transfirió a macetas para su posterior aclimatación bajo frascos de vidrio que fueron retirados gradualmente, hasta dejar a las plantas descubiertas, a los fines de proceder a su indexing para SPFMV, SPVG, SPVC, SPCSV y para geminivirus, en general. Las que no acusaron infección viral fueron macropropagadas bajo jaula anti-áfidos.

El control sanitario o indexing para los distintos virus se efectuó por medio de pruebas biológicas: injerto en la indicadora Ipomoea setosa (Martinelli, 2014); pruebas serológicas: en el caso de SPFMV, SPVG y SPVC, mediante NCM-ELISA con empleo de antisueros policlonales específicos (Parent et al., 1985) y para SPCSV, por TAS-ELISA (Gibson et al., 1998). La presencia de geminivirus en general. fue determinada a través de PCR (Li et al., 2004; Rodríguez Pardina et al., 2012b; Martino et al., 2017a), con empleo de los oligonucleóticos degenerados universales (SPG1 y SPG2) para geminivirus de batata, que amplifican fragmentos de aproximadamente $900 \mathrm{pb}$. Para ello, previamente se extrajo el ADN viral mediante empleo de $\mathrm{NaOH}$ y tampón Tris-ClH (Rodríguez Pardina et 
al., 2012b; Wang et al., 1993). El análisis de PCR para detección de geminivirus, fue realizado en plantas regeneradas del $\mathrm{cv}$. Arapey INIA y Beauregard, a la sexta semana de la siembra de meristemas. La observación de los viriones en savia infectada fue realizada a través de un microscopio electrónico de transmisión (MET) JEOL JEM EX II 1220®. Se hicieron preparados dips y de "decoración" en lo que las partículas fueron cubiertas con antisueros específicos contra SPFMV (Milne y Lesemann, 1978). Este método se utilizó especialmente para la detección de SPFMV y SPVG.

Por último, las plantas saneadas fueron propagadas, partiendo de una sola planta de Arapey INIA y de Beauregard. La misma se clonó en dos plantas y a las dos semanas, una se auto-injertó usando como púa una porción de su tallo (control sano) y la otra se infectó, injertando con una púa portadora del complejo viral EA (Martinelli, 2014). Ambas plantas (sana e infectada con EA) fueron multiplicadas vegetativamente, mediante trozos de guías puestos a enraizar en macetas con sustrato estéril adecuado, ubicadas en jaulas con malla antiáfidos en invernadero, hasta obtener suficiente material para el ensayo experimental de campo. Tanto plantas sanas como infectadas fueron controladas sanitariamente para los virus involucrados en el complejo EA, del modo antes descripto.

\section{Ensayo experimental de campo}

Se delineó un ensayo de campo a los fines de cuantificar el efecto del EA sobre componentes de rendimiento y contenido de clorofila de las dos variedades de batata.

El experimento se llevó a cabo bajo un diseño en parcelas divididas, distribuidas en tres repeticiones de 10 plantas cada una. En el mismo fueron asignados aleatoriamen- te dos factores, a parcela principal: "condición sanitaria", con dos niveles: plantas sanas e infectadas con EA y a parcela secundaria: "genotipos", también con dos niveles: Arapey INIA y Beauregard. De este modo, se conformaron cuatro tratamientos en total, resultantes de la combinación de los niveles de los dos factores.

El suelo, de tipo franco-arcilloso, fue acondicionado dos meses previos al trasplante a través de dos pasadas de rastra de doble acción y dos de motocultivador. Para el control de malezas en preemergencia, se aplicó Linurex (Linuron) al suelo previamente regado y oreado, a razón de $85 \mathrm{~cm}^{3}$ en $85 \mathrm{~m}^{2}$ de superficie. Además, antes de hacer los bordos, el suelo se desinfectó con Actara (Tiametoxam), para prevenir el ataque especialmente de "moscas blancas", en dosis de $0,5-0,7 \mathrm{~g} / 10 \mathrm{~m}$ lineales $(500-700 \mathrm{~g}$ ha $^{-1}$.) con un volumen de agua de 200-300 L ha $^{-1}$. Luego de realizar los bordos, de 0,30 m de altura y ubicados a 0,90 entre sí, se aplicó $1,10 \mathrm{~kg}$ urea en $85 \mathrm{~m}^{2}$ seguido de un riego ligero (Mwanga y Fuentes, 2010).

Para preservar la condición de plantas sanas, se sembró una barrera verde (sorgo granífero) de 1,5 $\mathrm{m}$ de ancho en la periferia del ensayo y de $3 \mathrm{~m}$, entre las parcelas sanas y las afectadas por EA. De esta manera, se pudo proteger el ensayo y minimizar el movimiento de insectos vectores (áfidos y moscas blancas) y, por ende, evitar la transmisión de virus desde las parcelas infectadas a las sanas. La barrera y el cultivo por evaluar fueron pulverizados regularmente de manera preventiva, con Confidor, (Imidacloprid), a razón de 30 g/10 L agua. Esto permitió eliminar los insectos interceptados en la barrera de sorgo (CABI. Plantwise Knowledge Bank, 2014; Muturi et al., 2007; Gibson et al., 2004; Ngailo et al., 2013). 
En noviembre, se efectuó el trasplante de plantines de tres nudos a $0,30 \mathrm{~m}$ entre sí. Cada parcela estuvo constituida por 60 plantas. Se regó por surco, acorde a las demandas ambientales, alcanzando su requerimiento cercano a $550-660 \mathrm{~mm}$ en todo el ciclo del cultivo (Martí, 2014).

\section{Contenido de clorofila}

Se evaluó el contenido relativo de clorofila en hojas de batata mediante lecturas de SPAD (Hansatech CL-01), registradas con un dispositivo portátil. Dicho contenido es determinado a partir de muestras de hojas, a través de valores de absorbancia óptica a longitud de onda dual (620 y $940 \mathrm{~nm})$ y se muestra en el rango de 0 a 2000 unidades. El valor SPAD refleja la concentración de clorofila en las hojas de las plantas de forma simple y rápida, sin daño de las mismas.

En este experimento, se realizaron mediciones en nueve momentos desde el trasplante, y los registros fueron: F1, F2, F3, F4, F5, F6, F7, F8 y F9, a las cinco (27/12), seis $(5 / 1)$, siete $(12 / 1)$, ocho $(19 / 1)$, nueve $(25 / 1), 10(2 / 2), 12(16 / 2), 14(2 / 3)$ у 16 (16/3) semanas, respectivamente. Para su evaluación, se seleccionaron e identificaron, de manera aleatoria, 10 plantas por tratamiento. Durante las determinaciones, se aplicó un mismo criterio que consistió en colocar el dispositivo en la nervadura central de la tercera y cuarta hoja expandida de la guía más larga.

Para el análisis de los valores de SPAD se utilizaron modelos lineales generales mixtos. Las comparaciones de medias se realizaron mediante Test de Fisher, con un nivel de significancia del 5\%. Los análisis se realizaron con el paquete estadístico Infostat (Di Rienzo et al., 2016).

\section{Estimación de componentes de rendimiento en plantas saneadas $y$ en plantas infectadas con $E A$}

Al momento de la cosecha, se midieron diferentes caracteres componentes de rendimiento in situ tales como: número de guías principales (NG), peso fresco de parte aérea (PFA), área foliar de la cuarta y quinta hoja de la guía más larga (AF) mediante software Hoja INTA (Verga, 2012), número de raíces totales (NTR), peso fresco de raíces totales (PTR), número de raíces comerciales (NRC) y peso fresco de raíces comerciales (PRC). Se consideraron comerciales a las raíces que superaron los $100 \mathrm{~g}$ de peso (Biderbost et al., 1990; Tolocka et al., 2013).

Los datos obtenidos fueron analizados estadísticamente mediante modelos lineales generales y mixtos (MLM) para establecer diferencias entre condiciones sanitarias (plantas sanas y enfermas) y genotipos (Arapey INIA y Beauregard). Las comparaciones de medias se realizaron a través de la prueba de Fisher, con nivel de significancia del $5 \%$.

Además, para cada variable, se determinaron las disminuciones potenciales porcentuales (porcentaje de daño) mediante la siguiente fórmula: $\mathrm{D}=\sum\left[\left(\dot{\mathrm{X}}_{\mathrm{s}}-\mathrm{Xi}\right) /\right.$ $\dot{X} \mathrm{~s}]^{*} 100$ (siendo Ẋs media de la variable en plantas asintomáticas, Xi valor de la variable en planta infectada con EA).

Con el fin de dilucidar los efectos directos e indirectos de los caracteres medidos en el rendimiento de las raíces se realizó un Análisis de Sendero (Path Analysis). Para los análisis se empleó el paquete estadístico Infostat (Di Rienzo et al., 2016). 


\section{RESULTADOS Y DISCUSIONES}

\section{Regeneración de dos cultivares de batatas} a partir de meristemas

Aplicación de las técnicas para la regeneración de plantas saneadas (termoterapia y cultivo "in vitro" de meristemas)

Se observó que el porcentaje de meristemas establecidos de Arapey INIA fue superior en relación con el de Beauregard $(40 \%$ vs $30 \%$ ), respectivamente. Beauregard exhibió elevado porcentaje de meristemas necrosados (67\%) respecto a Arapey INIA (23\%), lo que podría deberse principalmente a un efecto fitotóxico diferencial del hipoclorito de sodio durante la desinfección. Borges et al. (2004), encontraron diferen- cias en el efecto fitotóxico a distintas concentraciones de hipoclorito de sodio, en plantas leñosas. La contaminación en Arapey INIA (37\%), se debió principalmente a la presencia de bacterias y hongos.

\section{Control sanitario de las plantas \\ regeneradas (indexing de los virus presuntamente eliminados)}

Tal como se muestra en la Figura 1, no se detectaron geminivirus en las plantas regeneradas del cv Arapey INIA ni del cv Beauregard. Sólo se observó banda en el gel de agarosa en la calle correspondiente al control positivo (planta de batata fehacientemente infectada con geminivirus).

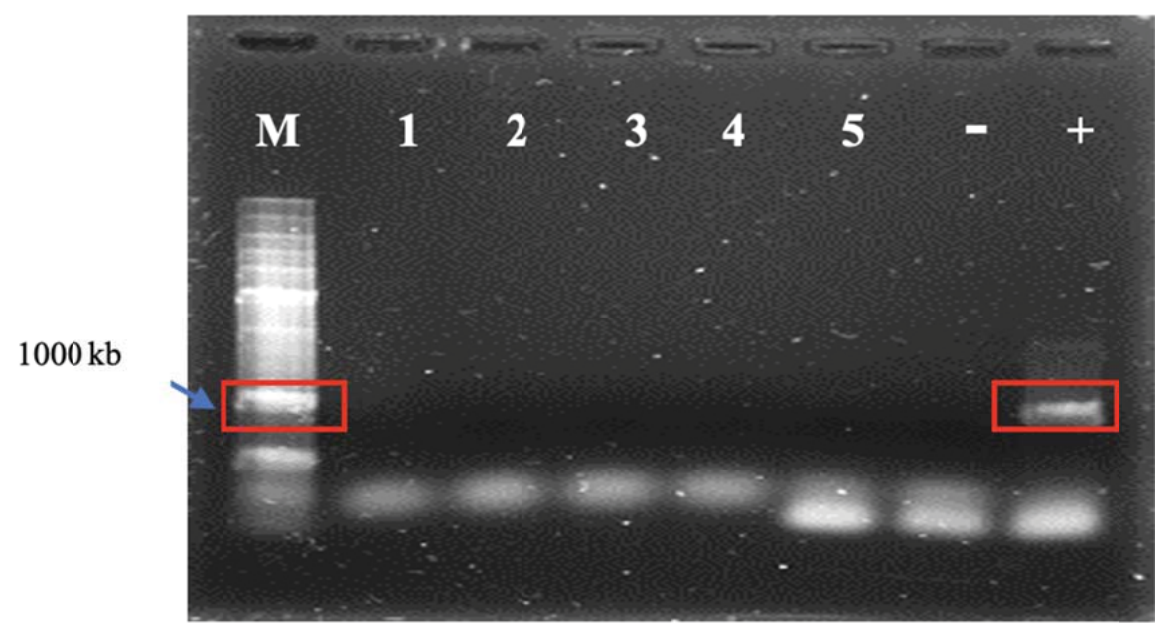

Figura 1. Detección molecular de geminivirus de batata. Electroforesis en gel de agarosa de los fragmentos de ácido nucleico (900kb) de geminivirus, amplificados por PCR. M: marcador de peso molecular, donde la banda señalada corresponde a 1000 pares de bases (KB), 1-3: Arapey INIA, 4-5: Beauregard, -: control negativo de virus (agua) y $+:$ control positivo de virus. Instituto de Patología Vegetal (INTA) Córdoba, 2018.

Figure 1. Molecular detection of sweet potato geminivirus. Agarose gel electrophoresis of PCR-amplified nucleic acid fragments (900kb) of geminivirus. M: molecular weight marker, where the marked band corresponds to 1000 base pairs (KB), 1-3: Arapey INIA, 4-5: Beauregard, -: negative virus control (water) and +: positive virus control. Instituto de Patología Vegetal (INTA) Cordoba, 2018. 
Observaciones al microscopio electrónico

En las observaciones al microscopio electrónico de los preparados dips realizados en plantas infectadas con EA, se observaron viriones filamentosos flexuosos, algunos de los cuales se decoraron con suero anti-SPFMV corroborando la presencia de este potyvirus en el complejo viral. También pudieron observarse otras partículas sin decorar con SPFMVas, correspondientes a SPVG y a SPCSV.

\section{Propagación de las plantas saneadas}

En Córdoba y en la mayor parte del país, los transplantes de batata, se realizan de manera estacional (octubre, noviembre y diciembre). A los fines de generar el factor "condición sanitaria" con dos niveles (plantas sanas y plantas infectadas con EA), ambas fueron mantenidas en jaulas separadas para preservar su estado sanitario.

A partir de la $4^{\circ}$ semana de practicado el injerto, las plantas correspondientes a la condición "infectada con EA" mostraron síntomas foliares notables (aclaramiento de nervadura generalizado, punteado clorótico, mosaico intenso) (Figura 2) y comenzaron a clonarse, de manera separada, hasta lograr el número necesario para realizar el ensayo comparativo de rendimiento (120 plantas en total, 60 de cada genotipo). Esto se logró a los 45 días desde el injerto.
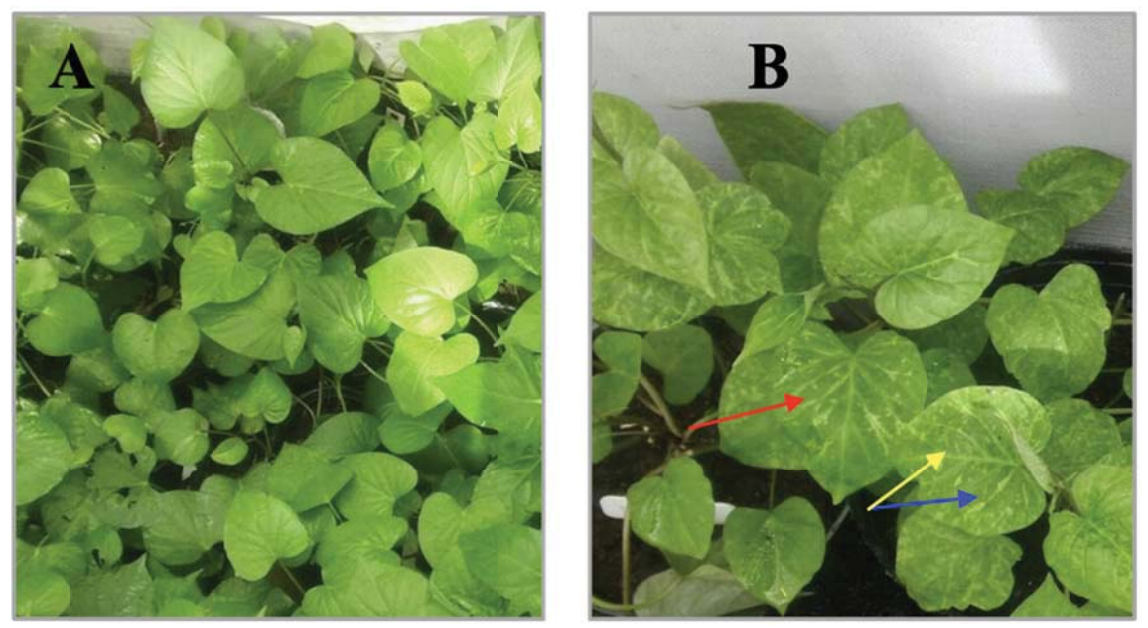

Figura 2. Multiplicación de plantas saneadas (A) y enfermas de EA (B) cv Beauregard, en jaulas con malla antiáfidos, mantenidas en invernadero. Presencia de sintomas foliares, bandeado nerval y aclaramiento de nervadura (flecha roja), punteado clorótico (flecha azul), mosaico con diseños cloróticos y distorsión de la lámina foliar (flecha amarilla). Instituto de Patología Vegetal (INTA) Córdoba, 2018.

Figure 2. Multiplication of healthy (A) and diseased plants of EA (B) cv Beauregard, in cages with anti-aphid mesh, kept in greenhouse. Presence of foliar symptoms, vein banding and vein clearing (red arrow), chlorotic spotting (blue arrow), mosaic with chlorotic patterns and leaf blade distortion (yellow arrow). Instituto de Patología Vegetal (INTA) Córdoba, 2018. 


\section{Contenido de clorofila}

En la Tabla 1 se observan los valores promedio, el error estándar y los valores máximo y mínimo para la variable SPAD (contenido de clorofila) en la F9 (16/03). Para Arapey INIA, el rango de variación fue diferente según condición sanitaria (valores mínimos y máximos de 16,2 y 25,4 para sanas y de 9,29 y 15,5 para enfermas). En el caso del cv Beauregard, el rango de variación se ubicó entre 14,8 y 21,6 y entre 7,8 y 15,7 , para las condiciones sana y enferma, respectivamente. Se pudieron observar reducciones notables de lecturas de SPAD, en presencia de EA.

El análisis estadístico permitió establecer diferencias altamente significativas $(\mathrm{p}<0,0001)$ para contenido de clorofila entre condición sanitaria, genotipo y momentos de medición: con valores promedio de 19,52 en sanas y 11,45 en enfermas, 15,92 y 15,05 para Arapey INIA y Beauregard, respectivamente, mientras que, para los momentos, éstos fueron de 14,28 (F1 - F4) y 16,45 (F5 - F9). Por otra parte, no se observó interacción significativa entre condición sanitaria y genotipo para el valor de $\operatorname{SPAD}(\mathrm{p}=0,20)$.

$\mathrm{Su}$ et al. (2009) demostraron la existencia de una correlación positiva altamente significativa entre los valores del SPAD y la concentración de clorofila en hojas de batata sana, aunque esta determinación aún no fue realizada en hojas de batata con EA. Pepó (2018) demostró la relación entre el contenido de clorofila en hojas de batata y el rendimiento del cultivo en diferentes métodos de plantación.

Los posibles efectos generados en las plantas enfermas evaluadas durante el período de fase 2 y principio de la fase final de crecimiento, se deberían a un retraso en los procesos de tuberización, además de una reducción de la actividad fotosintética. Según Zhang et al. (2020), ambos procesos se estimulan mutuamente y limitan la máxima eficiencia de la planta, afectando de manera indirecta al rendimiento. Los resultados obtenidos indicaron (datos no mostrados) que las lecturas de SPAD en hojas de plantas sanas, aumentaron de manera gradual durante el período de crecimiento desde principios de enero hasta mediados de febrero, seguido de una reducción a mediados de marzo, al final del período vegetativo. En plantas enfermas, los valores de contenido de clorofila se mantuvieron en un rango más reducido con respecto a plantas sanas durante el período evaluado, y EA ocasionó una significativa reducción de éstos. Experimentos realizados por Ananthu

Tabla 1. Porcentajes de regeneración y contaminación de meristemas de los cvs. Arapey INIA y Beauregard, a los 45 días desde la siembra.

Table 1. Percentages of regeneration and contamination of cvs. Arapey INIA and Beauregard meristems, 45 days after sowing.

\begin{tabular}{l|c|c|c}
\hline Cultivar & Establecidos & Muertos o necrosados & Contaminados \\
\hline Arapey INIA & $40 \%$ & $23 \%$ & $37 \%$ \\
\hline Beauregard & $30 \%$ & $67 \%$ & $3 \%$ \\
\hline
\end{tabular}


y Umamaheswaran (2019), han demostrado que en plantas infectadas con virus se produce una reducción significativa del contenido de clorofila. En plantas enfermas con EA, es notable el amarillamiento foliar (por merma del contenido de clorofilas) que da lugar a valores de SPAD reducidos con relación a los de plantas sanas. El análisis estadístico corrobora lo expresado, arrojando diferencias significativas entre condiciones sanitarias, pero no entre genotipos con igual estado de sanidad (Tabla 1).

\section{Estimación de componentes de rendimiento en plantas saneadas e infectadas con EA}

Se analizaron los componentes del rendimiento en Arapey INIA y Beauregard para la condición sana y enferma (Tabla 2). Al considerar la misma condición sanitaria (sana y enferma con EA), en el caso de las variables relacionadas con el crecimiento vegetativo (PFA, NG y AF), ambos genotipos (Arapey INIA y Beauregard) discreparon significativamente $(p<0,0001)$. En

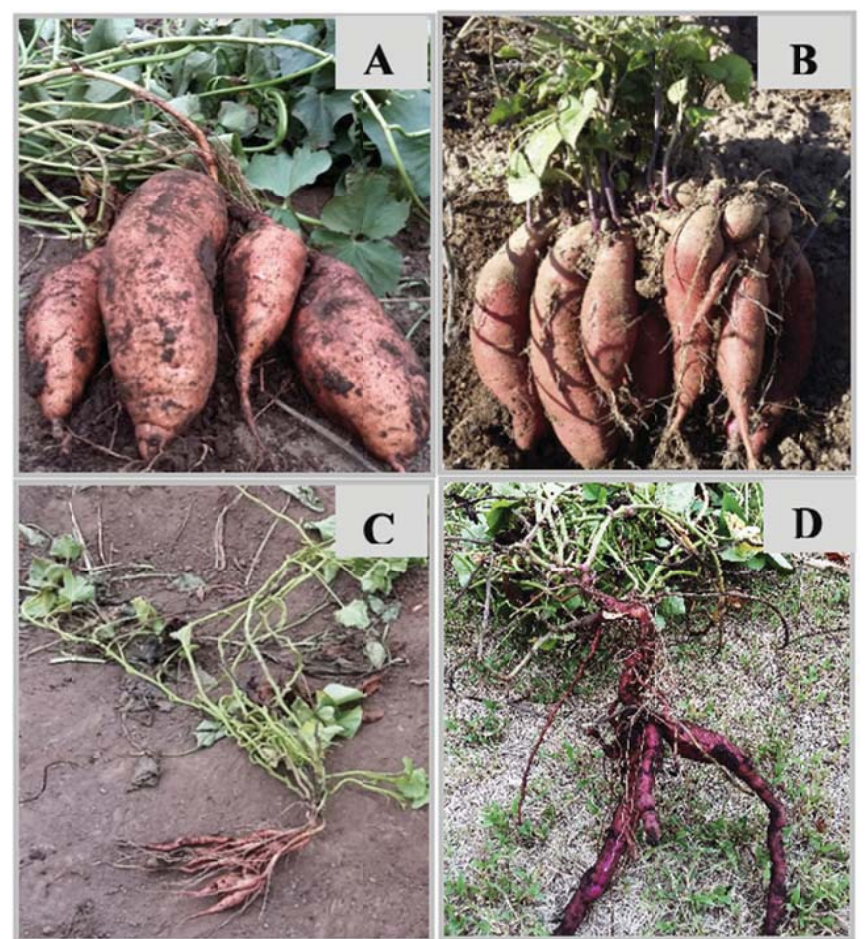

Figura 3. Raices reservantes provenientes de plantas sanas e infectadas con EA, respectivamente,

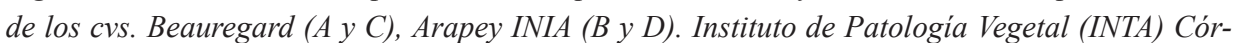
doba, 2019.

Figure 3. Sweet potato storage roots from healthy and EA infected plants, respectively, of cvs. Beauregard $(A$ and $C$ ) and Arapey INIA (B and D). Instituto de Patología Vegetal (INTA) Córdoba, 2019. 
Tabla 2. Medias y errores estándar de caracteres componentes del rendimiento en cvs Arapey INIA y Beauregard para las condiciones sanitarias sana y enferma.

Table 2. Means and standard errors of yield component characters in cvs. Arapey INIA and Beauregard for healthy and diseased conditions.

\begin{tabular}{|c|c|c|c|c|c|c|c|}
\hline Variable & PRC & NRC & PTR & PFA & NTR & NG & AF \\
\hline Arapey INIA & 1471,7 & 5,4 & 1745,6 & 2327,1 & 12,2 & 10,5 & 10,5 \\
\hline sana & $\pm 05,6 \mathrm{Ac}$ & $\pm 0,4 \mathrm{Ac}$ & $\pm 112,6$ Ac & $\pm 138,1 \mathrm{Ac}$ & $\pm 0,8 \mathrm{Ac}$ & $\pm 0,78 \mathrm{Ac}$ & $\pm 0,8 \mathrm{Ac}$ \\
\hline Arapey INIA & 248,8 & 1,2 & 446,8 & 1226,5 & 6,5 & 10,9 & 10,9 \\
\hline enferma & $\pm 109,5 \mathrm{Md}$ & $\pm 0,4 \mathrm{Md}$ & $\pm 116,7 \mathrm{Md}$ & $\pm 143,2 \mathrm{Md}$ & $\pm 0,8 \mathrm{Md}$ & $\pm 0,8 \mathrm{Mc}$ & $\pm 0,8 \mathrm{Md}$ \\
\hline Beauregard & 1469,5 & 4,8 & 1737,0 & 1172,4 & 10,3 & & 7,3 \\
\hline sana & $\pm 09,7 \mathrm{Ac}$ & $\pm 0,4 \mathrm{Ac}$ & $\pm 117,0 \mathrm{Ac}$ & $\pm 143,5$ Bc & $\pm 0,8 \mathrm{Ac}$ & $7,3 \pm 0,8 \mathrm{Bc}$ & $\pm 0,8 \mathrm{BC}$ \\
\hline Beauregard & 175,2 & 1,6 & 339,1 & 367,3 & 6,7 & & 5,9 \\
\hline enferma & $\pm 103,7 \mathrm{Md}$ & $\pm 0,4 \mathrm{Md}$ & $\pm 110,5 \mathrm{Md}$ & $\pm 135,6 \mathrm{Nd}$ & $\pm 0,8 \mathrm{Md}$ & $5,9 \pm 0,8 \mathrm{Nc}$ & $\pm 0,8 \mathrm{Nd}$ \\
\hline
\end{tabular}

Los datos corresponden a medias \pm errores estándar. Los valores en la misma columna con letras mayúsculas comparan diferentes cultivares de la misma condición sanitaria. Letras minúsculas comparan diferentes condiciones sanitarias del mismo cultivar. Medias con diferentes letras son significativamente diferentes $(P \leq$ 0,05).

cambio, para caracteres vinculados directa- tes del rendimiento para ambos genotipos mente con rendimiento (PRT, PRC, NTR y (Fig. 4) concuerdan con los determinados $\mathrm{NRC}$ ) no hubo diferencias entre cultivares por López Colomba et al. (2010), en el cv $(p>0,25)$. Las plantas sanas y enfermas de Arapey INIA.

ambos genotipos exhibieron diferencias altamente significativas $(\mathrm{p}<0,0001)$ para toDurante la década del 90, Biderbost et das las variables analizadas. al. (1990) estimaron el porcentaje de daño, causado por "enanismo clorótico" (EC)

La interacción entre condición sanitaria en el cv Morada INTA, para los diferentes y genotipo no fue significativa para ningu- componentes de rendimiento. Si bien las no de los caracteres analizados (ambos ge- mermas en plantas afectadas por esta ennotipos tuvieron igual comportamiento en fermedad fueron significativas para todos presencia de la virosis, con valores de sig- ellos, cabe destacar que el rendimiento exnificancia p de: 0,$30 ; 0,50 ; 0,59 ; 0,71 ; 0,18$; hibió una disminución del $60 \%$, mientras 0,64 y 0,30 para PFA, NG, NRC, PRC, que en este estudio pudo establecerse que NTR, PTR y AF, respectivamente). Los la misma resultó cercana al 90\%. Una de las daños estimados en caracteres componen- razones de esta diferencia podría deberse a 


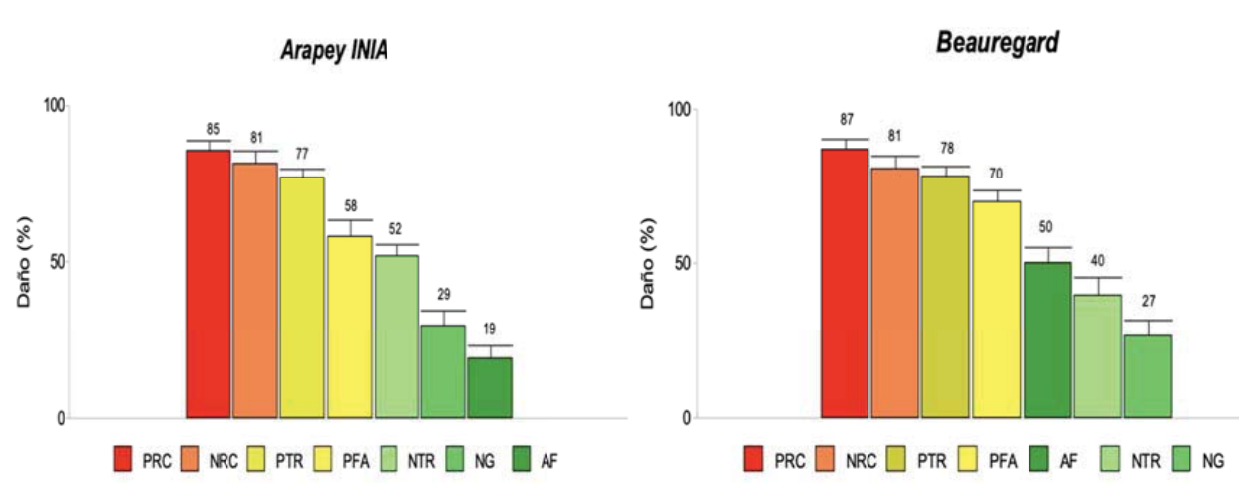

Figure 4. Porcentajes de daño (valores medios porcentuales de la variable en plantas infectadas con EA con relación a la media de las sanas) en los cvs Arapey INIA (izq.) y Beauregard (der.), respectivamente. Referencias: los valores que se muestran son los de media y el segmento sobre la barra es el error estándar.

Figure 4. Damage percentages (mean percentage values of the variable in plants infected with EA in relation to the mean of healthy plants) in cvs Arapey INIA (left) and Beauregard (right), respectively. References: The values shown are the mean values and the segment above the bar is the standard error.

que, mientras en el EC estaban involucradas tres especies virales, en la actualidad, al menos son siete las entidades que desencadenan la nueva virosis.

\section{Análisis de sendero (Path Analysis)}

Considerando a PRC como la variable más relevante de rendimiento, el análisis de sendero demostró que, tal como se esperaba, la misma estuvo directamente correlacionada con PTR, tanto para la condición sana como enferma, al tener en cuenta los efectos directos e indirectos (a través de las otras variables). (Para Arapey, los coeficientes ( $r$ total) fueron: $r=0,98 ; p<0,0001$ y $r=0,96 ; p<0,0001$, en plantas sanas y enfermas, respectivamente y de $\mathrm{r}=0,98$; $p<0,0001$, en sanas y $r=0,90 ; p<0,0001$, en enfermas, para Beauregard). Al tener en cuenta sólo el efecto directo de PTR sobre PRC, en Arapey INIA, la correlación directa entre PRC y PTR fue altamente sig- nificativa, aunque mayor en plantas sanas que en enfermas $(r=1 ; p<0,0001$ vs, $r=0,78$; $\mathrm{p}<0,0001)$. Igual situación se presentó para el cv Beauregard, ( $r=1,04 ; \mathrm{p}<0,0001$, en sanas vs, $r=0,80 ; p<0,0001$, en enfermas). La asociación entre PFA, NG, AF, NRC y NTR con PRC ocurrió de manera indirecta y altamente significativa, a través de PTR, y la magnitud de esta asociación dependió de la condición sanitaria y del genotipo (Figura 5). De los efectos indirectos sobre rendimiento (PRC), el de mayor relevancia fue NRC a través de PTR, y los coeficientes de correlación fueron superiores en plantas enfermas respecto a sanas en ambos genotipos.

Cabe destacar que en el caso del "enanismo clorótico" (EC), el carácter de mayor incidencia sobre número de raíces reservantes del cv Morada INTA era NRT (Biderbost et al., 1993). En cambio, para "encrespamiento amarillo", en Arapey INIA y en Beauregard, el efecto directo 
más significativo sobre PRC es el de PTR. racteres correlacionados con el rendimiento De este modo, y tal como ocurrió para el son diferentes en plantas infectadas con EA $\mathrm{EC}$, se comprueba que las variaciones en respeto a plantas sanas.

los efectos directos e indirectos de los ca-

A
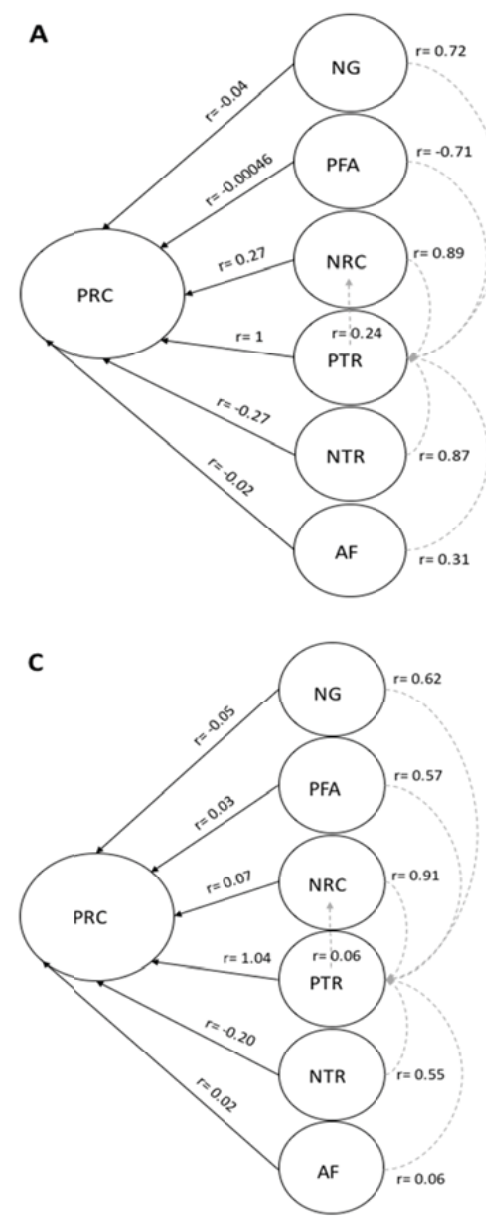
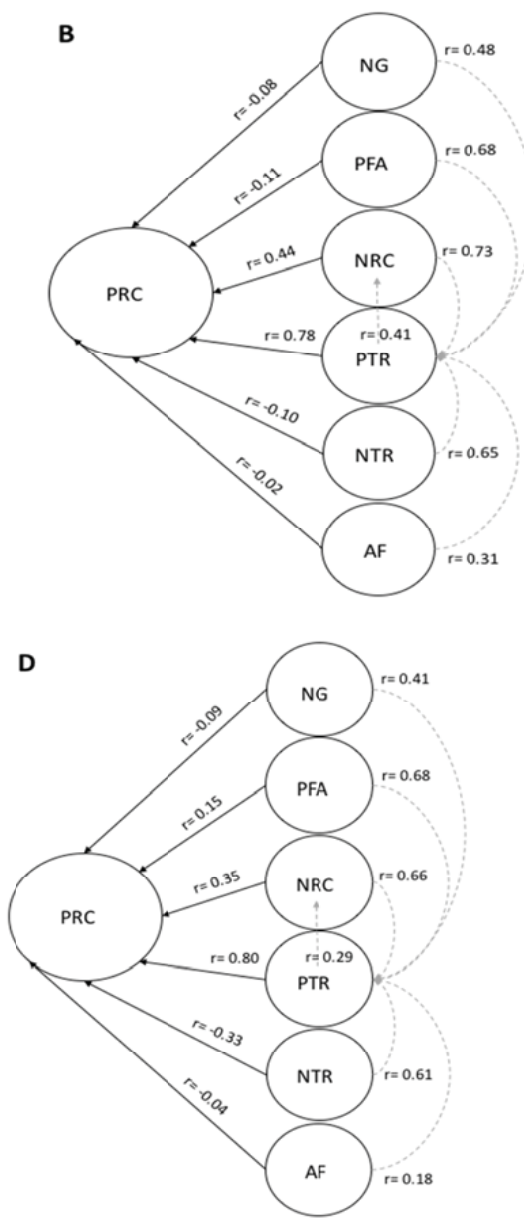

Figura 5. Análisis de sendero entre PRC y los caracteres componentes $N G, A F, N R C, P T R, N T R y$ PFA para la condición sanitaria sana y enferma de los cvs Arapey INIA (A y B) y Beauregard, (C y D) respectivamente. Lineas continuas indican efectos directos; lineas punteadas indican efectos indirectos sobre PRC.

Figure 5. Path analysis between PRC and the component traits NG, AF, NRC, PTR, NTR and PFA for the healthy and diseased health condition of the Arapey INIA cv (A and B) and Beauregard $(C$ and $D)$, respectively. Solid lines indicate direct effects; dotted lines indicate indirect effects on PRC. 


\section{CONCLUSIONES}

El EA causa una significativa disminución del contenido de clorofilas respecto a plantas sanas considerando ambos genotipos. Los cultivares Arapey INIA y Beauregard son similares entre sí en cuanto a contenido de clorofilas, independientemente de su condición sanitaria.

Los caracteres componentes del rendimiento sufren mermas significativas en plantas infectadas con EA de ambos genotipos, con porcentajes de daños en el peso de raíces comerciales de aproximadamente $90 \%$. Sólo en el caso de Beauregard, no hay diferencias entre plantas sanas e infectadas con EA para NG.

El carácter de mayor incidencia directa sobre el peso de raíces comerciales es el peso total de raíces, tanto en plantas sanas como enfermas (con EA).

Existe asociación indirecta altamente significativa entre PFA, NG, AF, NRC y NTR con PRC, a través de PTR, y la magnitud de ésta depende de la condición sanitaria y el genotipo.

\section{REFERENCIAS BIBLIOGRÁFICAS}

Ananthu N, Umamaheswaran K. 2019. Effect of viral infection on carbohydrate and chlorophyll Contents in Ginger (Zingiber officinale Rosc.). Int. J. Curr. Microbiol. App. Sci 8(6): 862-867.

Bejerman N, Zanini A, Rodríguez Pardina P, Di Feo L. 2016. Use of 454-Pyrosequencing for the Characterization of sweet potato virus $\mathrm{C}$ and sweet potato feathery mottle virus isolates from Argentina and development of a multiplex one-step RT-PCR for their simultaneous detection. Journal of Phytopathology. 164 (6):386-394.

Biderbost E, Brugnoni E, Mollinedo V, Di Feo L. 1990. Estimación de daños producidos por el sweet potato feathery mottle virus (SPFMV) en la cv Morada INTA de batata (Ipomoea batatas (L.) Lam). Revista de Investigaciones Agropecuarias (RIA) XXII. 251-255.

Biderbost E, Di Feo L, Mollinedo V. 1993. Asociaciones Fenotípicas entre rendimiento y caracteres componentes en plantas de batata (Ipomoea batatas (L.) Lam) cv Morada INTA sanas y afectadas por Enanismo Clorótico. Horticultura Argentina 8-12 (18-32):36-40.

Borges García M, Ros Araluce C, Castellanos Rubio Y, Milanes Rodríguez S, Velásquez Feria R. 2004. Efecto de diferentes métodos de desinfección en el establecimiento in vitro de Guadua angustifolia Kunth. Revista de Biotecnología Vegetal. 4 (4):237-242.

CABI. Plantwise Knowledge Bank. 2014. Pest Management Decision Guide: Green List. Sweet potato Virus Disease (SPVD). Complex of Sweet potato chlorotic stunt virus (SPCSV) and potyvirus sweet potato feathery mottle virus (SPFMV). https://www.plantwise.org/KnowledgeBank/pmdg/201478015 45

CIAT. Centro Internacional de Agricultura Tropical. 1982. El cultivo de meristemas para el saneamiento de clones de yuca. Guía de Estudio para ser usada como complemento de la Unidad Audiotutorial sobre el mismo tema. Pp. 45. Serie 04SC-02.05.

Clark CA, Davis JA, Abad J, Cuellar WJ, Fuentes S, Kreuze J, Gibson RW, Mukasa SB, Tugume AK, Tairo F, Valkonen JPT. 2012. Sweet potato viruses: 15 years of progress on understanding and managing complex diseases. Plant Dis. 96(2):168-185.

Di Feo L, Nome S, Biderbost E, Fuentes S, Salazar L. 2000. Etiology of Sweet Potato Chlorotic Dwarf Disease in Argentina. Plant Disease 84: 35-39. 
DiFeo L. 2015. Producción, multiplicación y manejo de propágulos de batata de sanidad controlada. Córdoba, Argentina. Secretaría de Ciencia y Tecnología. Ministerio de Industria, Comercio y Desarrollo Científico Tecnológico. Gobierno de la Provincia De Córdoba. Disponible en https:// www.researchgate.net/publication/288503472_ Produccion_multiplicacion_y_manejo_de_propagulos_de_batata_de_sanidad_controlada_Liliana_del_Valle_Di_Feo.

Di Rienzo J, Casanoves F, Balzarini M, Gonzalez L, Tablada M, Robledo C. InfoStat versión 2016. Grupo InfoStat, FCA, Universidad Nacional de Córdoba, Argentina.

Galvez M, Cuellar W, Fuentes S, Kreuze J. 2013. Caracterización molecular de aislamientos de sweepovirus que infectan Ipomoea batatas (L.) Lam. y estudio de sinergismo con el Sweet potato chlorotic stunt virus (SPCSV). In: Asociación Peruana de Fitopatología (APF). Libro de Resúmenes. 22. Congreso Peruano de Fitopatología. 17 Congreso Latinoamericano de Fitopatología (CPLAF - 2013). Lima, Perú. APF. Pp. 75.

Gibson R, Mpembe I, Alicai T, Carey E, Mwanga R, Seal S, Vetten H. 1998. Symptoms, etiology and serological analysis of sweet potato virus disease in Uganda. Plant Pathology 47: 95-102.

Gibson R, Aritua V, Byamukama E, Mpembe I, Kayongo J. 2004. Control strategies for sweet potato virus disease in Africa. Virus Research 100: 115-122.

Li R, Salih S, Hurtt S. 2004. Detection of Geminiviruses in Sweet potato by Polymerase Chain Reaction. Plant Disease 88:1347-1351.

Loebenstein G. (2015). Advances in Virus Research. Control of Plant Virus Diseases Vegetatively-Propagated Crops. Control of Sweet Potato Virus Diseases. 91:3345.

Loebenstein G, Thottappilly G, Fuentes S, Cohen J. 2009. Virus and Phytoplasma Diseases. En: Loebenstein G, Thottappilly G. 2009. The Sweet Potato. Pp. 105-131.
López Colomba E, Rodríguez Pardina P, Luque A, Nome C, Nome F, Di Feo L. 2011. Estimación de daños potenciales causados por virus involucrados en el "encrespamiento amarillo de la batata". 34 Congreso Argentino de Horticultura. Buenos Aires. Pp. 344.

López Colomba E, Luque A, Nome C, Grion A, Suasnabar R, Martí H, Di Feo L. 2010. Estimación en daños en caracteres componentes del rendimiento causados por una nueva virosis en batata (Ipomoea batatas (L.) Lam) cv Arapey INIA. XXXIII Congreso Argentino de Horticultura. Santa Fe. Horticultura Argentina Libro de Resúmenes. 29(70). Pp. 53.

Love S, Rhodes B, Moyer J. 1987. Meristem-tip culture and virus indexing of sweet potatoes. (Practical manuals for handling crop germplasm in vitro). International Board for Plant Genetic Resources (IBPGR), Rome, Italy. 46 p.

Martí H. 2014. Ciclo del cultivo y requerimientos ambientales. Cap. 2. En: Martí H, Mittidieri M, Di Feo L, Segade G, Constantino A. 2014. Producción agroecológica de batata para el gran cultivo y la huerta familiar. Editores: Martí H. INTA EEA San Pedro, Chianduzzi MC. Coordinación Nacional ProHuerta. Editorial: INTA. 75pp.

Martinelli D. 2014. Caracterización biológica y serológica de sweet potato virus G (SPVG) que infecta a cultivos de batata en Argentina. Tesina de Grado. FCEF y N. UNC. 73p.

Martino J, Fontenele R, Ribeiro S, Di Feo L. 2017a. First Report of Sweet potato leaf curl Georgia virus in Sweet potato in Argentina. Plant Disease. 101(3):513.

Martino J, Suasnabar R, Contardi C, Di Feo L. 2017b. Un nuevo patógeno afecta a los cultivos de batata en Argentina. Libro de Resúmenes del Cuarto Congreso Argentino de Fitopatología. Mendoza. Pp. 264.

Milne R, Leseman D. 1978. An immuno-electron microscopy investigation of oat sterile dwarf and related viruses. Virology. 90:299304. 
Murashige T, Skoog F. 1962. A revised medium for rapid growth and bioassays with tobacco tissue cultures. Physiol. Plant. 15:473-497.

Muturi P, Mwololo J, Mburu M, Njeru R, Kiarie N, Munyua J, Ateka E, Muinga R, Kapinga R, Lemaga B. 2007. Strategies of maintaining sweet potato nurseries free from insect vectors that spread sweet potato virus disease. African Crop Science Conference Proceedings. 8:2071-74.

Mwanga R, Fuentes S. 2010. Sweet potato. En: Quality declared planting material. Protocols and standards for vegetatively propagated crops. FAO Plant Production and Protection Paper 195. Pp. 81-88.

Ngailo S, Shimelis H, Sibiya J, Mtunda K. 2013. Sweet potato breeding for resistance to sweet potato virus disease and improved yield: Progress and challenges. African Journal of Agricultural Research 8. (25):3202-3215.

Nome S. 1973. Sweet potato vein mosaic virus in Argentina. Phytopathol Z. 77:44-54.

Nome S, Docampo D. 1974. Incidencia del virus del mosaico de las nervaduras (sweet potato vein mosaic virus) en rendimientos en batata. IDIA-INTA. 315:1-6.

Nome S, Salvadores C. 1980. Obtención de plantas de batatas (Ipomoea batatas L.) libres de virus. Rev. Fac. Cienc. Agrop. Univ. Nac. de Córdoba - Argentina. 1:87-96.

Nome C, Laguna I, Nome S. 2005. Cytological Alterations Produced by Sweet potato mild speckling virus (SPMSV). Journal of Phytopathology. 154:504-507.

Parent J, Berlanger F, Desjardins S, Brisson J. 1985. Dot-immunobinding for detection of tomato mosaic virus and potato virus $\mathrm{X}$, infecting greenhouse tomatoes. Phytoprotection. 66:53-57.

Pepó P. 2018. The effect of different planting methods on the yield and spad readings of sweet potato (Ipomoea batatas (L.). Colume- lla: Journal of Agricultural and Environmental Sciences 5:7-12.

Rodríguez Pardina P, Luque A, Nome C, López Colomba E, Fuentes Delgado S, Di Feo L. 2012a. First report of Sweet potato leaf curl virus infecting sweet potato in Argentina. Australasian Plant Dis. Notes. 7(1):157-160.

Rodríguez Pardina P, Bejerman N, Luque A, Di Feo L. 2012b. Complete nucleotide sequence of an Argentinean isolate of sweet potato virus G. Virus Genes. 45(3):593-595.

Salazar L. 1996. Potato Viruses and Their Control. Lima, Perú. International Potato Center. Pp. 69-74.

Su Y, Guo H, Yang X. 2009. Study on correlations between SPAD readings and chlorophyll content in leaves of sweet potato, dioscorea and konjaku. Southwest China Journal of Agricultural Sciences. 22(1):64-66.

Tolocka P, López Colomba E, Luque A, Rodríguez Pardina P, Di Feo L. 2012a. Estudios preliminares sobre la presencia de virus en zonas productoras de batata (Ipomoea batatas (L.) Lam) de Argentina. 35 Congreso Argentino de Horticultura. Corrientes. 31 (76).

Tolocka P, López Colomba E, Corbino G, Luque A, Suasnabar R, Martí H, Rodríguez Pardina P, Di Feo L. 2012b. Estimación experimental de daños causados por el "encrespamiento amarillo de la batata", Ipomoea batatas (L.) Lam., en el rendimiento del cultivar Arapey INIA. XIV Jornadas Fitosanitarias Argentinas. Potrero de los Funes. San Luis. Pp. 85.

Tolocka P, López Colomba E, Corbino G, Luque A, Suasnabar R, Zanini A, Martino J, Martí H, Rodríguez Pardina P, Di Feo L. 2013. Estimación de daños causados por un complejo viral en batata en Argentina. Estimated damages caused by a complex virus in sweet potato in Argentina. Actas del XXII Congreso Peruano y XVII Congreso Latinoamericano de Fitopatología. Lima. Perú. Pp. 125. 
Verga A. 2012. Hojas 3.4. Programa para la medición de caracteres morfológicos de hojas. INTA. IFFIVE. Córdoba, Argentina.

Wang H, Qi M, Cutler A. 1993. A simple method of preparing plant samples for PCR. Nucleic Acids Research 21:4153-4154.

Wang L, Poque S, Valkonen JPT. 2019. Phenotyping viral infection in sweet potato using a high-throughput chlorophyll fluorescence and thermal imaging platform. Plant Methods. 15:116.

Zhang K, Lu H, Wan C, Tang D, Zhao Y, Luo K, Li S, Wang J. 2020. The spread and transmission of sweet potato virus disease (SPVD) and its effect on the gene expression profile in sweet potato. Plants. 9(4):492. 